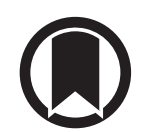

CrossMark

\section{Cough sensitivity to mannitol inhalation challenge identifies subjects with chronic cough}

\author{
To the Editor:
}

Cough is the most common reason why people seek medical attention [1]. Cough hypersensitivity syndrome (CHS) is a new concept to describe a condition with long-standing hypersensitivity of vagal afferent nerves or an alteration of the central processing of their input regardless of the underlying cause [2]. The current definition of CHS is purely clinical; however, a test capable of demonstrating this hypersensitivity both reliably and feasibly might be used as a diagnostic test for CHS.

The traditional cough provocation tests using capsaicin or citrate are limited by a wide normal range of the responses [3] and the measured cough sensitivity poorly correlates with the subjective symptoms [4]. Cough provocation testing using hypertonic saline can separate asthmatic from healthy subjects [5] and the level of cough responsiveness is correlated with the subjective symptoms [6]. However, this test requires complex technology and therefore may not be feasible to diagnose CHS.

The mannitol challenge is a regulatory approved bronchial provocation test. It is similar to hypertonic saline, providing an osmotic stimulus to airways and provoking cough, but can be administered using a simple powder inhaler [7,8]. Thus, it might be a feasible diagnostic test for CHS. Cough sensitivity to mannitol separates asthmatic subjects from healthy subjects [7]. However, another study found a large overlap in the cough sensitivity to mannitol between healthy subjects and subjects with chronic cough [9]. The present study was performed to determine whether cough sensitivity to mannitol inhalation challenge can separate subjects with chronic cough from those without, and whether subjective cough severity is associated with the cough sensitivity to mannitol.

This was a prospective study including 15 healthy subjects and 69 consecutive symptomatic patients who were referred to a respiratory function laboratory for mannitol challenge as part of their clinical evaluation. Among the symptomatic patients, there were 17 subjects with chronic (over 8 weeks' duration) cough as their primary symptom. This group was defined as the "cough" group and the remaining 52 as the "other symptoms" group (usually dyspnoea or wheezing).

All subjects completed the Leicester Cough Questionnaire (LCQ) [10]. Increasing doses of mannitol powder were administered starting with an empty capsule, followed by 5, 10, 20, 40, 80, 160, 160 and $160 \mathrm{mg}$ doses [11]. $60 \mathrm{~s}$ after each dose, two forced expiratory volume in $1 \mathrm{~s}$ (FEV1) manoeuvres were obtained. The challenge was video recorded and two scorers counted the coughs afterwards. The mean value was used for analysis. The cough sensitivity to mannitol was expressed by coughs-to-dose ratio (CDR), the total number of provoked coughs divided by the cumulative amount of mannitol, expressed as coughs per $100 \mathrm{mg}$ of mannitol [7], and by C5, the first noncumulative mannitol dose that provoked five or more coughs. Mann-Whitney and Kruskal-Wallis tests were used to analyse differences between groups, and Spearman correlation coefficient ( $\mathrm{rs}$ ) to analyse associations. The study protocol was approved by the Ethics Review Committee of the Sydney Local Health District (Royal Prince Alfred Hospital zone), number X11-0249.

The mean (95\% CI) age of the subjects was 34.3 (31.2-37.5) years with 50\% females. The mean FEV1 was $101 \%(98-104 \%)$ of predicted among the symptomatic subjects and 15 of them showed a $>15 \%$ fall in FEV1 during the challenge.

@ERSpublications

Mannitol challenge is a promising diagnostic test for cough hypersensitivity syndrome http://ow.ly/gWf530j9O7H

Cite this article as: Koskela HO, Lake C, Wong K, et al. Cough sensitivity to mannitol inhalation challenge identifies subjects with chronic cough. Eur Respir J 2018; 51: 1800294 [https://doi.org/10.1183/ 13993003.00294-2018]. 
The cough group was significantly more sensitive to the cough-provoking effect of mannitol than the subjects with other symptoms and the healthy subjects (CDR 21.1 (12.6-35.4), 6.2 (4.2-9.4) and 2.8 (1.3-6.1) coughs per $100 \mathrm{mg}$, respectively; $\mathrm{p}<0.001$ between cough and healthy subjects (figure 1), and $\mathrm{p}=0.002$ between cough and other symptoms; C5 9.2 (5.8-14.7), 57.3 (38.9-84.6) and 116 (60.0-225) mg, respectively; $\mathrm{p}<0.001$ between cough and healthy subjects, and $\mathrm{p}<0.001$ between cough and other symptoms). There was a significant association between the LCQ total score and CDR both within the group "cough" $(\mathrm{r} s=0.50, \mathrm{p}=0.04)$ and within all symptomatic subjects $(\mathrm{r} s=0.43, \mathrm{p}<0.001)$. The cough sensitivity to mannitol was higher in women than in men among the symptomatic subjects (CDR 18.4 (12.9-26.2) versus 4.3 (2.6-7.0) coughs per $100 \mathrm{mg}$, respectively; $\mathrm{p}<0.001)$.

The present study demonstrates that the cough sensitivity to mannitol inhalation challenge clearly separates subjects with chronic cough both from healthy subjects and from subjects with other airway symptoms. Furthermore, mannitol cough sensitivity was correlated with the LCQ, a validated cough-related quality of life questionnaire.

Our study corroborates the previous studies with asthmatic patients in finding a large difference and small overlap in the cough sensitivity to hypertonicity between healthy subjects and the subjects with cough $[5,7,12]$. However, there is a previous mannitol study showing a relatively large overlap [9]. The main reason for this discrepancy is probably the very mild cough among the patients in the previous study. The mean LCQ total score was 17.3 among the chronic cough patients and 20.9 among the healthy subjects, with the difference just reaching statistical significance. By comparison, the mean LCQ total score among the subjects with chronic cough in the present study was 13.9, indicating much more severe cough. The present and the previous mannitol study differ also in many other aspects, including the ways in which the coughs were recorded and how the response was expressed.

As mentioned, the traditional cough provocation tests using capsaicin or citrate usually show a wide normal range of the responses [3] and the measured cough sensitivity correlates poorly with the subjective symptoms [4]. Thus, there are important differences between traditional cough provocation tests and hypertonic aerosol cough provocation tests. The reasons for these are not clear. Capsaicin and, at least partly, citrate act via directly stimulating the transient receptor potential vanilloid 1 (TRPV1) receptor in the sensory nerves [13]. On the contrary, hypertonicity does not stimulate TRPV1 [14]. The most probable receptor to detect changes in osmotic homeostasis is TRPV4 [13]. Afferent A $\delta$ and C fibres with cell bodies located in jugular ganglia are specifically sensitive to hypertonicity [15]. The repeatedly documented association between the cough sensitivity to hypertonicity and the subjective cough severity suggests that these fibres play a key role in CHS.

The fact that mannitol challenge not only measures the cough sensitivity but also the airway hyperresponsiveness is clinically useful, providing the possibility to simultaneously diagnose asthma, one of the most common causes of chronic cough.

There are several shortcomings in the present study. It would have been desirable for the group "cough" to be larger. More information about the cough background disorders would also have been useful. The strengths of the study include the representative sample of patients: they were referred to a respiratory function laboratory by independent physicians as part of real-life clinical evaluation. The accurate way of recording the coughs is also strength, as the challenges were video recorded and two scorers counted all coughs from the recordings afterwards.

FIGURE 1 The coughs-to-dose ratios (CDRs) among 15 healthy subjects and 17 subjects with chronic cough $(p<0.001$ between the groups, Mann-Whitney test). The best cut-off value to separate the groups was 12.0 coughs per $100 \mathrm{mg}$. The vertical axis is logarithmic.

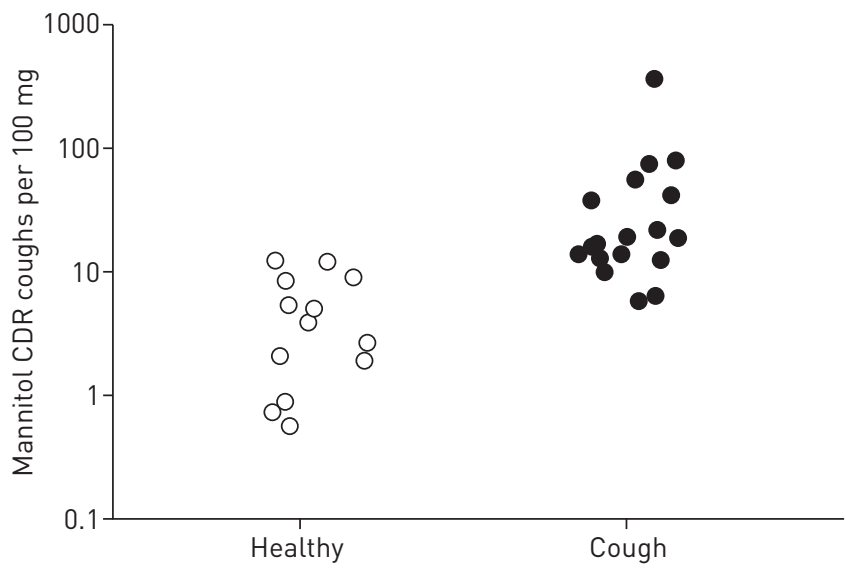


In conclusion, the cough sensitivity to mannitol can identify subjects with chronic cough and this sensitivity is associated with the subjective cough severity. Since the mannitol challenge is regulator approved and can be performed without complex technology in a highly standardised fashion, it seems to be a promising diagnostic test for CHS. Studies with larger and better defined populations are now warranted.

Heikki O. Koskela ${ }^{1,2}$, Clair Lake ${ }^{3,4}$, Keith Wong ${ }^{3,4}$ and John D. Brannan ${ }^{5}$

${ }^{1}$ Unit for Medicine and Clinical Research, Pulmonary Division, Kuopio University Hospital, Kuopio, Finland. ${ }^{2}$ School of Medicine, Institute of Clinical Sciences, Faculty of Health Sciences, University of Eastern Finland, Kuopio, Finland. ${ }^{3}$ Dept of Respiratory and Sleep Medicine, Royal Prince Alfred Hospital, Camperdown, Australia. ${ }^{4}$ Central Clinical School, Faculty of Medicine, The University of Sydney, Sydney, Australia. ${ }^{5}$ Dept of Respiratory and Sleep Medicine, John Hunter Hospital, New Lambton, Australia.

Correspondence: Heikki O. Koskela, Unit for Medicine and Clinical Research, Pulmonary Division, Kuopio University Hospital, PL 100, 70029 KYS, Finland. E-mail: heikki.koskela@kuh.fi

Received: Aug 162017 | Accepted after revision: March 062018

Acknowledgements: The authors would like to acknowledge the assistance of Peter Briffa and Phillip Munoz (both Dept of Respiratory Sleep Medicine, Royal Prince Alfred Hospital, Camperdown, and Central Clinical School, Faculty of Medicine, The University of Sydney, Sydney, Australia) with their assistance in the cough counting.

Author contributions: All authors made substantial contributions to the conception and design of the work, and acquisition, analysis or interpretation of data for the work, drafted the article or revised it critically for important intellectual content, and gave final approval of the version to be published. All authors agreed to be accountable for all aspects of the work, in ensuring that questions related to the accuracy or integrity of any part of the work are appropriately investigated and resolved.

Conflict of interest: H.O. Koskela reports receiving grants from Kuopion Hengityssäätiö, personal fees from Mundipharma Ltd, Orion Pharma Ltd, Oy, Eli Lilly Finland Ltd and Boehringer Ingelheim Finland Ltd as payments for giving scientific lectures at gatherings organised by medical companies, and personal fees from Takeda Leiras Ltd and Mundipharma Ltd to visit international scientific meetings, and owns shares in Orion Pharma Ltd. C. Lake reports that the Royal Prince Alfred Hospital receives royalties for the sale of Aridol but no longer receives royalties for sales in Australia. K. Wong reports that the Royal Prince Alfred Hospital receives royalties for the sale of Aridol but no longer receives royalties for sales in Australia. J.D. Brannan reports receiving royalties for the sale of Aridol/Osmohale and owns shares in Pharmaxis.

\section{References}

1 Centers for Disease Control and Prevention. National Ambulatory Medical Care Survey: 2010 Summary Tables. www.cdc.gov/nchs/data/ahcd/namcs_summary/2010_namcs_web_tables.pdf Date last updated: September 15, 2014. Date last accessed: November 15, 2017.

2 Morice AH, Faruqi S, Wright CE, et al. Cough hypersensitivity syndrome: a distinct clinical entity. Lung 2011; 189: 73-79.

3 Morice AH. Chronic cough hypersensitivity syndrome. Cough 2013; 9: 14

4 Birring SS, Matos S, Patel RB, et al. Cough frequency, cough sensitivity and health status in patients with chronic cough. Respir Med 2006; 100: 1105-1109.

5 Koskela HO, Purokivi MK, Kontra KM, et al. Hypertonic saline cough provocation test with salbutamol pre-treatment: evidence for sensorineural dysfunction in asthma. Clin Exp Allergy 2008; 38: 1100-1107.

6 Purokivi M, Koskela H, Kontra K. Determinants of asthma control and quality of life in stable asthma: evaluation of two new cough provocation tests. Clin Respir J 2013; 7: 253-260.

7 Koskela HO, Hyvarinen L, Brannan JD, et al. Coughing during mannitol challenge is associated with asthma. Chest 2004; 125: 1985-1992.

8 Lipworth BJ, Short PM, Williamson PA, et al. A randomized primary care trial of steroid titration against mannitol in persistent asthma: STAMINA trial. Chest 2012; 141: 607-615.

9 Singapuri A, McKenna S, Brightling CE. The utility of the mannitol challenge in the assessment of chronic cough: a pilot study. Cough 2008; 4: 10.

10 Birring SS, Prudon B, Carr AJ, et al. Development of a symptom specific health status measure for patients with chronic cough: Leicester Cough Questionnaire (LCQ). Thorax 2003; 58: 339-343.

11 Brannan JD, Anderson SD, Perry CP, et al. The safety and efficacy of inhaled dry powder mannitol as a bronchial provocation test for airway hyperresponsiveness: a phase 3 comparison study with hypertonic (4.5\%) saline. Respir Res 2005; 6: 144 .

12 Purokivi M, Koskela HO, Koistinen T, et al. Utility of cough response during hypertonic histamine challenge in diagnosing asthma. Respir Med 2008; 102: 1379-1384.

13 Belvisi MG, Birrell MA. The emerging role of transient receptor potential channels in chronic lung disease. Eur Respir J 2017; 50: 1601357.

14 Lalloo UG, Fox AJ, Belvisi MG, et al. Capsazepine inhibits cough induced by capsaicin and citric acid but not by hypertonic saline in guinea pigs. J Appl Physiol (1985) 1995; 79: 1082-1087.

15 Pedersen KE, Meeker SN, Riccio MM, et al. Selective stimulation of jugular ganglion afferent neurons in guinea pig airways by hypertonic saline. J Appl Physiol (1985) 1998; 84: 499-506. 